\title{
Repeated courses of antenatal corticosteroids have adverse effects on aspects of brain development in naturally delivered baboon infants
}

\author{
Amy Shields ${ }^{1}$, Merran Thomson ${ }^{2}$, Vicki Winter ${ }^{3}$, Jacqueline Coalson ${ }^{3}$ and Sandra Rees ${ }^{1}$
}

\begin{abstract}
INTRODUCTION: Repeated courses of antenatal steroids in women at risk of preterm delivery have beneficial effects on lung maturation, but concern exists about the effects on brain development. We aimed to determine whether repeated courses of corticosteroids increased the risk of neuropathology as compared with single courses or no treatment.
\end{abstract}

METHODS: Single-course animals received a 6-mg dose of steroids at 123 and $124 \mathrm{~d}$ of gestation (dg; term, $185 \mathrm{dg} ; n=6$ ). Repeated-course animals received additional doses at 137 and $138 \mathrm{dg}(n=7)$. Controls received no steroids $(n=5)$. Baboons delivered naturally at term and necropsy was performed. Brains were assessed histologically for parameters of development and neuropathology.

RESULTS: Body weights did not differ between the groups $(P>0.05)$; neither did brain/body weight ratio. Density of glial fibrillary acidic protein (GFAP)-immunoreactive (IR) astrocytes in white matter (WM) was increased in the single- $(P<0.05)$ and repeated-course $(P<0.01)$ groups as compared with controls. Density of myelin basic protein (MBP)-IR oligodendrocytes was reduced in the repeated-course animals as compared with both the control and single-course groups $(P<0.05)$; oligodendrocyte transcription factor 2 (Olig2)-IR showed no difference between groups.

DISCUSSION: Repeated courses of antenatal corticosteroids have effects on myelination in the developing nonhuman primate brain, which should be taken into account when determining a dosing regimen.

$\mathbf{R}^{\mathrm{o}}$ outine administration of antenatal steroids to mothers who are at risk of delivering prematurely has resulted in improved outcomes for preterm infants. Benefits to the newborn include a reduction of the risk of respiratory distress syndrome and intraventricular hemorrhage and reduced mortality and reliance on respiratory support (1). There is evidence that the effectiveness of antenatal corticosteroids diminishes with time (2), so if birth did not occur within $7 \mathrm{~d}$ of corticosteroid administration it was previously common practice to administer a second course of corticosteroids $(3,4)$. Concerns about the safety of this practice were raised following the publication of cohort studies $(5,6)$.
Randomized, controlled trials of repeated weekly or biweekly courses of antenatal steroids demonstrated improved neonatal respiratory outcomes (7); however, this was coupled with a reduction in some measures of weight and head circumference at birth $(7,8)$. Several longer-term studies have shown no impact of repeated courses of corticosteroids on physical growth or neurodevelopmental outcome at 2 years of age (9-11); however, other studies suggest a higher rate of cerebral palsy (12), neurodevelopmental abnormalities (13), and behavioral effects (14) in infants exposed to repeated courses of corticosteroids.

Studies in sheep have shown a dose-dependent effect of corticosteroids on birth weight (15) and that a reduction in brain weight following antenatal corticosteroid administration persists to 3.5 years of age (adulthood in the sheep; ref. 16). Other animal studies have shown that repeated courses of antenatal steroids can have detrimental effects on the developing brain, delaying myelination (17-19) and causing cell death in the hippocampus (20); a single course has been reported to reduce neural cell proliferation in rats (21) and alter cytoskeletal protein and synaptophysin in baboon brains (22).

Therefore, in light of evidence of possible adverse effects on the developing brain, the question as to whether obstetricians should continue to give repeated courses of corticosteroids remains controversial (23-25). A recent meta-analysis (26) concludes that repeated betamethasone restricts intrauterine growth, with possible long-term consequences on neurodevelopment.

In this study, we had the opportunity to investigate the developmental sequelae of single or repeated courses of antenatal corticosteroids as compared with no treatment in a nonhuman primate model, the baboon. We have shown previously that this model is appropriate for studying neuropathology due to its similarity with human brain development although the baboon brain reaches a more mature state by birth (27-29). Our experiment was designed to assess the effects of antenatal corticosteroid treatments when gestation was not affected by confounding factors such as hypoxia or malnutrition and when offspring were delivered naturally at term ( $185 \mathrm{~d}$ of gestation $(\mathrm{dg})$ in the baboon). Our aim was to determine whether a single course of corticosteroids at $123-124 \mathrm{dg}$ (66\% of gestation, equivalent to 
$\sim 26$ wk of gestation in the human; ref. 29) or repeated courses administered at 123-124 dg and 137-138 dg (74\% of gestation, equivalent to $\sim 30 \mathrm{wk}$ of gestation in the human; ref. 29) increased the risk of altered brain development (including deficits in myelination) or neuropathology (including astrogliosis, microgliosis, apoptosis) as compared with no treatment.

\section{RESULTS}

\section{Group Characteristics}

There was no difference between groups $(P>0.05)$ in the age at delivery (control: $186.0 \pm 0.71$; single course: $186.2 \pm 0.17$; repeated course: $186.4 \pm 0.37$ ) or the ratios of males to females (control: $2 / 3$; single course: $4 / 2$; repeated course: $4 / 3$ ).

\section{Brain Growth and Development}

Body weights at necropsy did not differ between the groups $(P>$ 0.05; Table 1). Total brain and cerebellar weights were increased in the single-course group as compared with both controls and the repeated-course group $(P<0.05$; Table 1$)$; there was no difference between groups in either brain or cerebellar weights when expressed in relation to body weight $(P>0.05$; Table 1$)$.

The volume of deep gray matter was reduced in the repeated-course group as compared with the control group $(P<0.05$; Table 2$)$, but this was not significant when expressed relative to total forebrain volume. There were no differences in other volumetric parameters between the groups (Table 2). The overall surface folding index between groups was not different $(P>0.05$; Table 2).

\section{Neuropathology}

There was no evidence of cerebral infarction, cystic lesions, or intraventricular hemorrhage in the cerebral hemispheres of any animal.

There was no difference between groups in the density of glial fibrillary acidic protein (GFAP)-immunoreactive (IR) astrocytes in the neocortex $(P>0.05$; Table 3$)$; however, in the deep and subcortical white matter (WM), the density of astrocytes was increased in both the single- and the repeated-course groups as compared with controls $(P<0.05$; Table 3$)$. This is illustrated for the deep WM by comparing GFAP-IR from the

Table 1. Effects of prenatal steroids on body and brain weights

\begin{tabular}{|c|c|c|c|}
\hline & $\begin{array}{l}\text { Term control } \\
\quad(n=5)\end{array}$ & $\begin{array}{l}\text { Single course } \\
\quad(n=6)\end{array}$ & $\begin{array}{c}\text { Repeated } \\
\text { course }(n=7)\end{array}$ \\
\hline $\begin{array}{l}\text { Body weight at } \\
\text { postmortem (g) }\end{array}$ & $846 \pm 68$ & $991 \pm 74$ & $864 \pm 44$ \\
\hline Total brain weight (g) & $78.1 \pm 1.7$ & $94.5 \pm 4.7^{* * * * * *}$ & $81.2 \pm 2.2$ \\
\hline Brain/body weight (\%) & $9.7 \pm 0.8$ & $9.5 \pm 0.3$ & $9.2 \pm 0.3$ \\
\hline Cerebellar weight (g) & $5.5 \pm 0.4$ & $7.0 \pm 0.3^{*, * * *}$ & $5.6 \pm 0.2$ \\
\hline $\begin{array}{l}\text { Cerebellar/body } \\
\text { weight }(\%)\end{array}$ & $0.70 \pm 0.03$ & $0.72 \pm 0.03$ & $0.64 \pm 0.03$ \\
\hline $\begin{array}{l}\text { Cerebellar/brain } \\
\text { weight }(\%)\end{array}$ & $7.2 \pm 0.4$ & $7.6 \pm 0.3$ & $7.1 \pm 0.2$ \\
\hline \multicolumn{4}{|c|}{ Data are presented as mean \pm SEM. } \\
\hline \multicolumn{4}{|c|}{$\begin{array}{l}{ }^{*} P<0.05 \text { as compared with controls; }{ }^{* *} P<0.01 \text { as compared with controls; }{ }^{* *} P<0.05 \\
\text { as compared with repeated course. }\end{array}$} \\
\hline
\end{tabular}

single- (Figure 1b) and repeated-course (Figure 1c) groups with controls (Figure 1a).

There was no difference in the areal density of oligodendrocyte transcription factor 2 (Olig2)-IR cells between groups in either region. This is illustrated by comparing the control group (Figure 1d) with the single-course (Figure 1e) and repeatedcourse (Figure 1f) groups. Myelin basic protein (MBP)-IR cell density in repeated-course animals was lower than controls and single-course animals in both the deep and subcortical WM $(P<0.05$; Table 3$)$; this is illustrated for the subcortical WM by comparing MBP-IR from repeated-course animals (Figure 1i) with controls (Figure 1g) and single-course animals (Figure $1 \mathrm{~h}$ ). The intensity of MBP-IR, as assessed by dark-field illumination in the corpus callosum, was reduced markedly in the repeated-course group (Figure 11), and was reduced mildly in the single-course group (Figure 1k) as compared with controls (Figure $\mathbf{1 j}$ ).

There was no difference between groups in the density of ionized calcium-binding adapter molecule 1-IR cells in cortex, deep, or subcortical WM $(P>0.05$; Table 3$)$.

Histological analysis revealed no overt damage and no consistent abnormalities in the morphology of CA1-3 pyramidal

Table 2. Forebrain volumetric parameters

\begin{tabular}{|c|c|c|c|}
\hline & $\begin{array}{l}\text { Term control } \\
\quad(n=5)\end{array}$ & $\begin{array}{l}\text { Single course } \\
\qquad(n=6)\end{array}$ & $\begin{array}{c}\text { Repeated } \\
\text { course }(n=7)\end{array}$ \\
\hline $\begin{array}{l}\text { Volume of the } \\
\text { (right) forebrain } \\
\left(\mathrm{mm}^{3}\right)\end{array}$ & $35,338 \pm 2,068$ & $34,957 \pm 1,719$ & $31,328 \pm 1,370$ \\
\hline $\begin{array}{l}\text { Neocortical } \\
\text { volume }\left(\mathrm{mm}^{3}\right)\end{array}$ & $21,240 \pm 1,283$ & $21,277 \pm 993$ & $19,787 \pm 1,032$ \\
\hline $\begin{array}{l}\text { White matter } \\
\text { volume }\left(\mathrm{mm}^{3}\right)\end{array}$ & $9,415 \pm 735$ & $9,351 \pm 419$ & $8,342 \pm 593$ \\
\hline $\begin{array}{l}\text { Deep gray } \\
\text { matter volume } \\
\left(\mathrm{mm}^{3}\right)\end{array}$ & $3,884 \pm 205$ & $3,558 \pm 158$ & $3,202 \pm 176^{*}$ \\
\hline $\begin{array}{l}\text { Ventricular } \\
\text { volume }\left(\mathrm{mm}^{3}\right)\end{array}$ & $658 \pm 93$ & $640 \pm 55$ & $564 \pm 70$ \\
\hline $\begin{array}{l}\text { Neocortex/total } \\
\text { hemispheric } \\
\text { volume (\%) }\end{array}$ & $61.2 \pm 0.7$ & $62.1 \pm 1.5$ & $64.3 \pm 1.3$ \\
\hline $\begin{array}{l}\text { White matter/ } \\
\text { total hemispheric } \\
\text { volume (\%) }\end{array}$ & $27.1 \pm 1.0$ & $27.3 \pm 0.5$ & $27.0 \pm 1.1$ \\
\hline $\begin{array}{l}\text { Deep gray matter/ } \\
\text { total hemispheric } \\
\text { volume (\%) }\end{array}$ & $11.2 \pm 0.3$ & $10.4 \pm 0.5$ & $10.5 \pm 0.6$ \\
\hline $\begin{array}{l}\text { Ventricular } \\
\text { volume/total } \\
\text { hemispheric } \\
\text { volume (\%) }\end{array}$ & $1.9 \pm 0.2$ & $1.9 \pm 0.1$ & $1.8 \pm 0.2$ \\
\hline $\begin{array}{l}\text { Neocortical } \\
\text { volume/white } \\
\text { matter volume }\end{array}$ & $2.3 \pm 0.1$ & $2.3 \pm 0.1$ & $2.4 \pm 0.1$ \\
\hline SFI & $82.0 \pm 2.3$ & $87.2 \pm 3.1$ & $79.0 \pm 1.9$ \\
\hline
\end{tabular}


Table 3. Forebrain neuroglial cell densities

\begin{tabular}{|c|c|c|c|}
\hline & $\begin{array}{l}\text { Term control } \\
\quad(n=5)\end{array}$ & $\begin{array}{l}\text { Single course } \\
\quad(n=6)\end{array}$ & $\begin{array}{c}\text { Repeated } \\
\text { course }(n=7)\end{array}$ \\
\hline \multicolumn{4}{|l|}{ GFAP-IR cells } \\
\hline Cortex & $5 \pm 2$ & $6 \pm 2$ & $3 \pm 1$ \\
\hline Subcortical WM & $305 \pm 23$ & $480 \pm 31^{*}$ & $473 \pm 27^{*}$ \\
\hline DeepWM & $277 \pm 18$ & $445 \pm 35^{*}$ & $548 \pm 55^{* *}$ \\
\hline \multicolumn{4}{|l|}{ Olig2-IR cells } \\
\hline Subcortical WM & $311 \pm 16$ & $309 \pm 14$ & $285 \pm 25$ \\
\hline Deep WM & $356 \pm 13$ & $358 \pm 11$ & $355 \pm 32$ \\
\hline \multicolumn{4}{|l|}{ MBP-IR cells } \\
\hline Subcortical WM & $126 \pm 15$ & $136 \pm 5$ & $83 \pm 9 *, * * *$ \\
\hline Deep WM & $179 \pm 12$ & $170 \pm 12$ & $136 \pm 6^{* * * * * *}$ \\
\hline \multicolumn{4}{|l|}{ Iba1-IR cells } \\
\hline Cortex & $66 \pm 3$ & $67 \pm 2$ & $60 \pm 3$ \\
\hline Subcortical WM & $103 \pm 6$ & $113 \pm 6$ & $104 \pm 6$ \\
\hline Deep WM & $148 \pm 8$ & $165 \pm 10$ & $148 \pm 14$ \\
\hline \multicolumn{4}{|c|}{ All measurements cells/mm². Data are presented as mean \pm SEM. } \\
\hline \multicolumn{4}{|c|}{$\begin{array}{l}\text { GFAP, glial fibrillary acidic protein; Iba1, ionized calcium-binding adapter molecule 1; } \\
\text { IR, immunoreactive; MBP, myelin basic protein; Olig2, oligodendrocyte transcription } \\
\text { factor 2; WM, white matter. }\end{array}$} \\
\hline \multicolumn{4}{|c|}{$\begin{array}{l}{ }^{*} P<0.05 \text { as compared with controls; }{ }^{* *} P<0.01 \text { as compared with controls; }{ }^{* * *} P<0.05 \\
\text { as compared with single course. }\end{array}$} \\
\hline
\end{tabular}

cells or of dentate granule cells in corticosteroid-treated animals as compared with controls. Apoptotic cells were observed infrequently $\left(\sim 1.4\right.$ cells $\left./ \mathrm{mm}^{2}\right)$ in the CA1-3 region of controls (Figure 2a) and corticosteroid-treated animals (Figure 2b,c).

\section{Relationship Between Myelination and Brain Volumes}

There were positive correlations between the density of MBP-IR cells in the WM and the volume of the right hemisphere $\left(r^{2}=0.31\right.$; $P<0.03)$, the deep gray matter $\left(r^{2}=0.31 ; P<0.03\right)$, and the neocortex $\left(r^{2}=0.23 ; P<0.03\right)$. These correlations occurred across all groups, and are consistent with normal brain growth. There were no other correlations across all parameters tested.

\section{DISCUSSION}

These studies were designed to determine whether single or repeated courses of antenatal corticosteroids in fetuses not exposed to any other factors such as hypoxia or infection affect brain development at normal term delivery. The main finding was that repeated courses have a greater effect on the brain than a single course, delaying myelination and causing a reduction in the volume of the deep gray matter; this reduction, however, was not reflected in an altered brain/body weight ratio. Both single and repeated courses of corticosteroids led to astrogliosis in the deep and subcortical WM, suggesting that steroids might be causing some brain injury although there were no overt signs of cell death or infarction at birth. Alterations could be present at the microstructural and/or neurochemical level, but we were unable to address these issues in this study. A strength of the study is that it was performed with nonhuman primates where, as in humans, major events in brain development occur in utero and the brain has similar proportions of gray and WM. The course of antenatal steroids used in this study is identical to that used in previous studies of the $125 \mathrm{dg}$ baboon model (31). The dose is half that used in humans to reflect the differing body weight of a pregnant baboon and human. The dose exposure was, therefore, similar to that in humans and given in an appropriate time frame to observe any intrauterine developmental alterations. We acknowledge that the baboon brain is more developed than the human brain at birth (29). In a companion study on the lung by our group, it has been shown that lung volumes are increased and there was a decrease in mesenchyme in the alveolar walls, suggesting antenatal corticosteroids may have an impact on the connective tissue matrix (unpublished data).

\section{Overall Brain Growth Was Not Affected by Single- or Repeated- Course Corticosteroids}

The body weight of animals at postmortem was not different between single-course, repeated-course, and control groups. Whole-brain and cerebellar weights of the single-course infants were significantly greater than both control and repeated-course infants, although this was not significant when expressed in relation to body weight. Volumetric measurements did not exhibit any differences between groups apart from a reduction in the deep gray matter volume in the repeated-course group as compared with controls. Again, this was not significant when expressed in relation to body weight. Furthermore, there was no difference in surface folding index between groups, indicating that gyral formation was not affected. Taken together, it would appear that these regimens of antenatal steroid treatment did not have a marked effect on overall brain growth. Other animal studies have found differences in body and brain weight in the short (32) and long term (16), but these involved different dosing regimens and species from those used here. Intrauterine growth restriction can result from antenatal corticosteroid treatment in humans, but this usually follows several courses of corticosteroids (26) as compared with the two courses administered in this study.

\section{Repeated Courses of Corticosteroids Delay Myelination}

We identified that repeated but not single courses of antenatal steroids affected myelination in the developing subcortical and deep WM, as indicated by lower numbers of MBP-IR cells as compared with controls. Furthermore, qualitative assessment of MBP-IR in the corpus callosum revealed a marked reduction in the repeated-course group and a mild reduction in the single-course group as compared with controls. As it was only possible to examine the effects of steroids at one time point, we are unable to determine whether myelination recovers to control levels postnatally. We do know, however, that the density of Olig2-positive cells was not different between groups at term. As Olig2 is a transcription factor that marks all cells of the oligodendrocyte lineage (33), we suggest that myelination is most likely to be delayed rather than permanently reduced; long-term studies will be required to confirm this.

Although this is the first study to describe alterations to myelination in a nonhuman primate as a result of repeated exposure to antenatal corticosteroids, previous studies have shown that repeated courses administered to fetal sheep result in delayed 

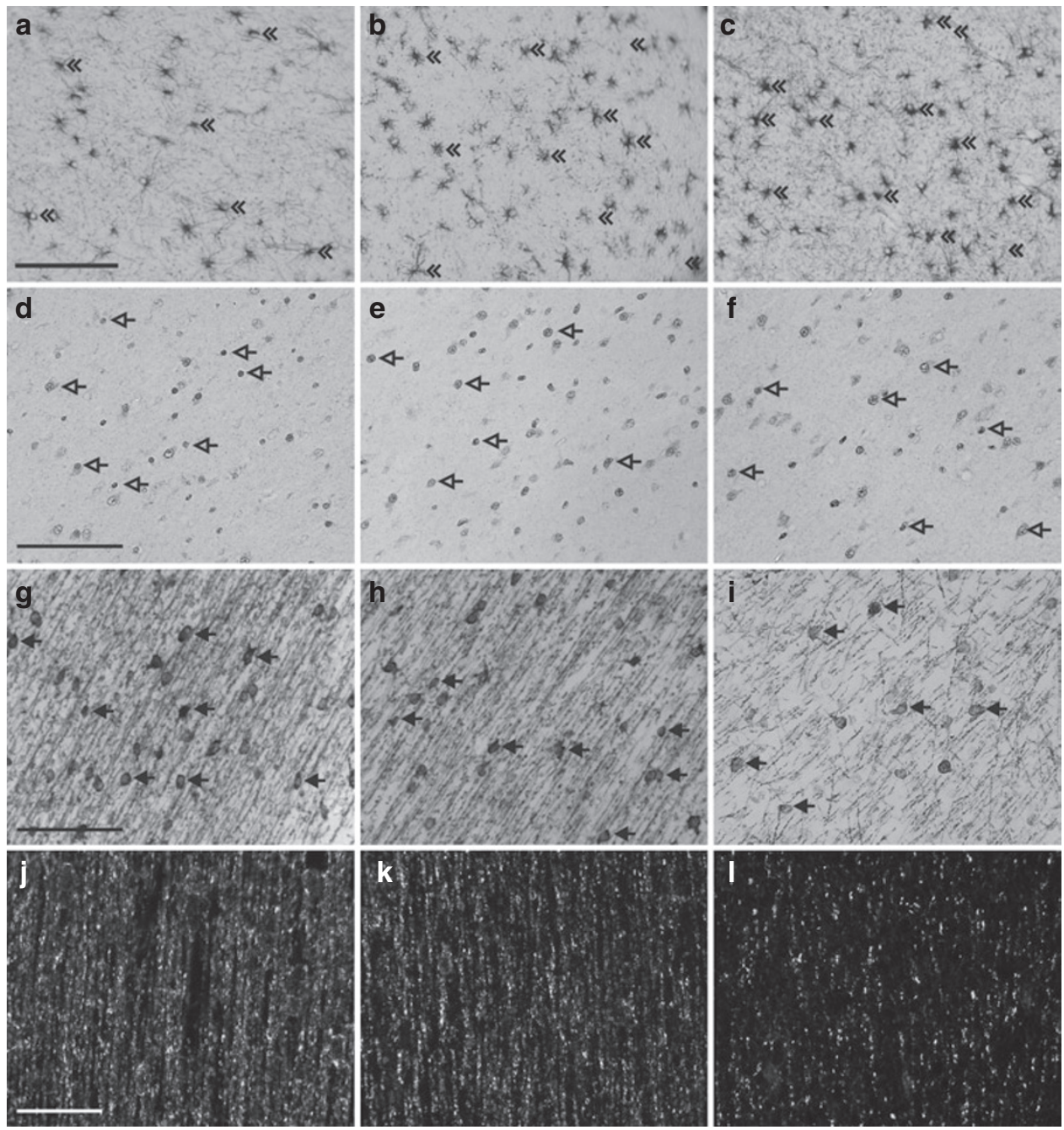

Figure 1. Effect of steroids on neuroglia in WM. Areal density of GFAP-IR astrocytes (arrowheads) in deep WM as compared with (a) controls was increased in both (b) single- and (c) repeated-course groups. Olig2-IR oligodendrocytes (open arrows) did not differ between (d) control, and (e) single- and (f) repeated-course groups (subcortical WM). Areal density of MBP-IR cells (filled arrows, subcortical WM) was reduced in the (i) repeated-course group as compared with both $(\mathbf{g})$ controls and the (h) single-course group. MBP-IR in the corpus callosum, viewed under dark-field illumination, was markedly reduced in the (I) repeated-course group and mildly reduced in the (k) single-course group as compared with (j) controls. Bar $=\mathbf{a}-\mathbf{f}, 100 \mu \mathrm{m} ; \mathbf{g}-\mathbf{i}, 50 \mu \mathrm{m}$. GFAP, glial fibrillary acidic protein; IR, immunoreactive; MBP, myelin basic protein; Olig2, oligodendrocyte transcription factor 2; WM, white matter.

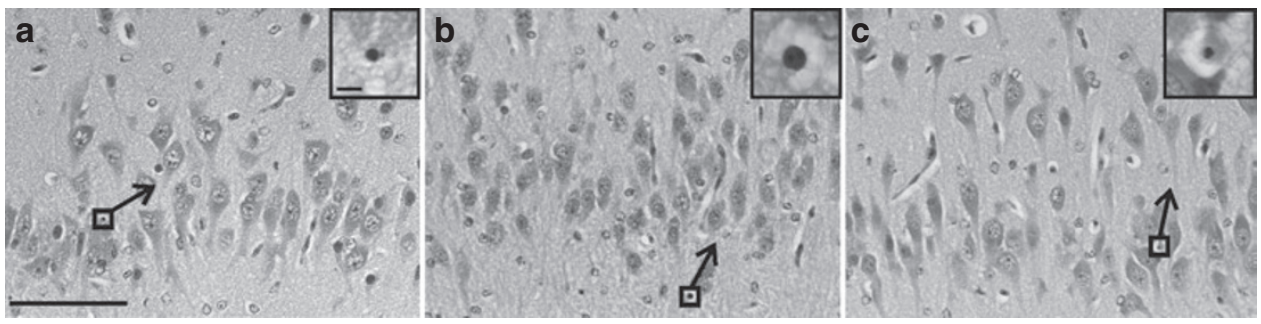

Figure 2. Hematoxylin and eosin staining. Similar levels of apoptosis are seen in the hippocampus across (a) control, and (b) single- and (c) repeated-course groups. Inset shows apoptotic cells (from boxed region) at higher magnification. Bar = a-c, $100 \mu \mathrm{m}$; $\mathbf{a}-\mathbf{c}$ inset, $5 \mu \mathrm{m}$.

myelination in the corpus callosum at term (17). A similar regimen delays myelination in the optic nerve during gestation (19), but recovery occurs by term. The authors suggest that regional differences in the effects of corticosteroids on the central nervous system might be due to the greater maturity of the optic nerve, where $10 \%$ of the fibers are myelinated at the time of the first injection of corticosteroids (17). Myelination in the baboon has already begun in the cerebral WM but not in the corpus callosum at the time of the first course of corticosteroids (29).With a single course of antenatal steroids, myelination in 
the deep and subcortical WM is not different from controls at term; however, there is a mild reduction in MBP-IR in the corpus callosum. We suggest that the more mature oligodendrocytes in the deep and subcortical WM recover from any adverse effects by term but that the less mature oligodendrocyte lineage in the corpus callosum sustains a mild deficit in myelination. In preterm baboons exposed to an additional course of steroids, the pool of vulnerable pre-oligodendrocytes is further affected, delaying their maturation and resulting in reduced myelination at term in all regions. Oligodendrocytes are known to be at particular risk of damage or altered function during the peak period of myelination (34).

Even if myelination reaches normal levels postnatally, it is possible that maturational delays might influence functional outcomes. Myelin thickness affects axonal conduction velocity (35) and, thus, influences latency of action potentials in cerebral fiber tracts; this could affect synchrony of neuronal firing. Synchronous activity of neurons is thought to be important for refinement of connections (36). A recent study of developing human brain using magnetic resonance imaging tractography supports the concept that appropriate development of myelinated axons plays an important role in optimizing connectivity (37). A delay in myelination at critical periods of brain development could conceivably affect connectivity and underlie long-term deficits in function.

As indicated earlier, it seems most likely that myelination is affected via effects of glucocorticoids on myelin synthesis rather than the death of oligodendrocytes. Glucocorticoids can act via genomic or nongenomic mechanisms, or alternatively by inducing effects on membranes (18). Glucocorticoids have been shown to act on post-transcriptional processes influencing the production of specific components of myelin, including glycerol phosphate dehydrogenase, MBP, and proteolipid protein (38).

\section{Neuropathology}

Both single and repeated courses of corticosteroids caused astrogliosis in the subcortical and deep WM as compared with controls, suggesting that exogenous steroids might trigger an underlying adverse event that results in a gliotic response; cellular damage can cause sustained astrocytosis in developing brain (39). However, there was no evidence of any infarction, hemorrhage, overt signs of neuronal or axonal damage, or increased microglial invasion when assessed in the hemispheres at postmortem. Qualitative examination of the hippocampus showed that apoptosis was not increased in corticosteroidtreated animals as compared with controls; we acknowledge that unbiased stereological counting is required to unequivocally determine whether neuronal death has occurred. A study of repeated corticosteroid administration in macaques demonstrated death of hippocampal pyramidal cells in animals delivered prematurely (20); in animals delivered at term alterations in the hippocampus were still present, but to a lesser degree (20). It is possible that in our study, injury had occurred earlier in gestation in response to exogenous steroids but cellular debris had been removed prior to postmortem; this might also explain the lack of persistent microgliosis.

\section{Conclusion}

In conclusion, we have shown that, in a nonhuman primate model at term, repeated courses of antenatal corticosteroids affect brain development more significantly than a single course, particularly in relation to myelination. Whether myelination recovers postnatally with further development is unknown; however, the integrity of the oligodendrocyte lineage would provide a basis for this to occur. The functional significance of a maturational delay in myelination is not known but could have long-lasting effects on brain function. Overall, brain growth in relation to body growth was not affected by corticosteroid treatment, but there was evidence of astrogliosis in both groups of treated animals, suggesting that there might be some underlying brain injury. In relating our findings to the human infant, we acknowledge that there are limitations of our study, including the small number of animals and the short duration of the study. However, our results suggest that repeated courses of corticosteroids are associated with a higher risk of brain alterations than a single course. Adverse effects on brain development will need to be balanced against the requirement to promote lung development when deciding whether to give repeated courses.

\section{METHODS}

All animal studies were performed at the Southwest Foundation for Biomedical Research in San Antonio, Texas. All animal husbandry, animal handling, and procedures were reviewed and approved by the institutional animal use and care committees of the Southwest Foundation for Biomedical Research and the University of Texas Health Science Center of San Antonio and conformed to American Association for Accreditation of Laboratory Animal Care guidelines.

Timed gestations were determined by observing characteristic sex skin changes and confirmed by serial fetal ultrasound examinations. Pregnant baboon dams (Papio papio) were randomly assigned to one of the following groups: the single-course group $(n=6)$ received a dose of antenatal steroids $(6 \mathrm{mg}$ betamethasone intramuscularly or $6 \mathrm{mg}$ dexamethasone intramuscularly), at 123 and $124 \mathrm{dg}$; the repeated-course group $(n=7)$ received an additional two doses, one at $137 \mathrm{dg}$ and one at $138 \mathrm{dg}$; a third, control, group received no placebo injections or sham handling procedures and served as the no-antenatal-steroid-treatment group $(n=5)$. Betamethasone was administered as a mixture of $3 \mathrm{mg} / \mathrm{ml}$ betamethasone acetate and $3 \mathrm{mg} / \mathrm{ml}$ betamethasone phosphate. Access to betamethasone was stopped by the supplier over a period of time during this study; dexamethasone had to be substituted, but this resulted in no discernible differences in outcome. All dams delivered air-breathing infants naturally at term (185 d). Necropsy was performed 1-2 d after delivery.

\section{Histology and Immunohistochemistry}

Brains were weighed, immersed in $4 \%$ paraformaldehyde or $10 \%$ formalin in $0.1 \mathrm{~mol} / \mathrm{l}$ phosphate buffer and $14-15$ blocks from the right forebrain (5-mm intervals) were processed to paraffin. Ten coronal sections $(8-\mu \mathrm{m}$ thick) were cut from the rostral surface of each block. One section per block was stained with hematoxylin and eosin and assessed for gross morphologic changes, including the presence of hemorrhages, lesions or infarcts, neuronal death, axonal injury, gliosis, and perivascular cuffing.

Immunohistochemistry for rabbit anti-cow-GFAP (1:500; Sigma, St Louis, MO) was used to identify astrocytes, and rabbit anti-ionized calcium-binding adapter molecule 1 (1:1,500; Wako, Richmond, VA) was used to identify microglia/macrophages. To identify cells in the oligodendrocyte lineage, mouse anti-chicken MBP (1:100; Chemicon, Temecula, CA) and rabbit anti-Olig2 polyclonal antibody (1:200; Chemicon) were used. Analyses were performed on all brains in 
the study. Qualitative and quantitative measurements were made on coded slides blinded to the observer.

\section{Analysis}

For each animal, all quantitative measurements were made using an image analysis system (Image Pro v4.1; Media Cybernetics, Bethesda, MD). Areas analyzed for density measurements within specific regions were randomly selected by an independent observer. Values were calculated as mean of means for each group; measurements of cell numbers are expressed as cells $/ \mathrm{mm}^{2}$.

The cross-sectional area of the forebrain in each coronal section (right hemisphere, 14-15 sections/brain) was assessed by tracing the outline in thionin-stained sections and the total forebrain volume estimated using the Cavalieri principle (volume $=\sum$ Area $\times$ section thickness $\times$ inverse of sampling interval; ref. 30). The total volume of WM, deep gray matter (basal ganglia, thalamus, and hippocampus), ventricle, and neocortex were also assessed in this manner for each animal. The surface folding index, which gives an estimation of the expansion of the surface area relative to volume, was then determined (29).

For each animal in the study, five sections were taken at comparable levels of the rostrocaudal extent of the forebrain; in each section GFAP-IR cells were counted $\left(\times 300\right.$; sample area $\left.0.02 \mathrm{~mm}^{2}\right)$ in two randomly selected regions of the deep and subcortical WM and one region in each of the dorsal, lateral, and ventral neocortex (layers 2-4).

For each animal in the study, five sections were taken at comparable levels of the rostrocaudal extent of the forebrain and MBP-IR and Olig2-IR oligodendrocytes counted $(\times 300)$ in two randomly selected areas $\left(0.02 \mathrm{~mm}^{2}\right)$ in both the deep and subcortical WM. Dark-field images were taken of the corpus callosum in MPB-IR sections to qualitatively assess the extent of myelination within this structure.

Ionized calcium-binding adapter molecule 1-IR cells were counted in the WM and neocortex of five sections (selected as described earlier) from each animal. In each section, cells were counted in three randomly selected regions in the neocortex (dorsal, lateral, and ventral; $\times 300$; sample area $0.02 \mathrm{~mm}^{2}$ ) and two randomly selected regions of each of the deep and subcortical WM $\left(\times 300\right.$; sample area $\left.0.02 \mathrm{~mm}^{2}\right)$.

For each animal, two hematoxylin and eosin-stained sections at comparable levels of the hippocampus were selected and a qualitative morphological analysis performed to assess the presence of any overt damage, to assess the morphology of hippocampal pyramidal and dentate granule cells, and to identify the presence of apoptotic cells.

\section{Statistical Analysis}

Differences between single-, repeated-course, and control animals were assessed using a one-way ANOVA with post hoc test (Tukey's test) for histologic parameters; a probability of $P<0.05$ was considered significant. Linear regression analysis was carried out to determine whether there was a correlation between histologic parameters (astrocyte, oligodendrocyte, and microglia/macrophage cell densities) and volumetric measurements; a probability of $P<0.05$ was considered significant. Results are expressed as mean \pm SEM (weights and areas) and mean of means \pm SEM (histologic parameters).

\section{ACKNOWLEDGMENTS}

We acknowledge the major role that Terrie Inder has played in the premature baboon project. We are grateful to Rachael O'Dowd for her technical assistance and Michelle Loeliger for advice with tissue preparation and analysis.

\section{STATEMENT OF FINANCIAL SUPPORT}

This study was supported by National Institutes of Health grants HL52636 and P51 RR13986.

\section{REFERENCES}

1. Roberts D, Dalziel S. Antenatal corticosteroids for accelerating fetal lung maturation for women at risk of preterm birth. Cochrane Database Syst Rev 2006;19:CD004454.

2. McLaughlin KJ, Crowther CA, Walker N, Harding JE. Effects of a single course of corticosteroids given more than 7 days before birth: a systematic review. Aust N Z J Obstet Gynaecol 2003;43:101-6.
3. Quinlivan JA, Evans SF, Dunlop SA, Beazley LD, Newnham JP. Use of corticosteroids by Australian obstetricians-a survey of clinical practice. Aust N Z J Obstet Gynaecol 1998;38:1-7.

4. Empana JP, Anceschi MM, Szabo I, Cosmi EV, Breart G, Truffert P; EURAIL Study Group. Antenatal corticosteroids policies in 14 European countries: factors associated with multiple courses. The EURAIL survey. Acta Paediatr 2004;93:1318-22.

5. French NP, Hagan R, Evans SF, Godfrey M, Newnham JP. Repeated antenatal corticosteroids: size at birth and subsequent development. Am J Obstet Gynecol 1999;180:114-21.

6. Banks BA, Cnaan A, Morgan MA, et al. Multiple courses of antenatal corticosteroids and outcome of premature neonates. North American Thyrotropin-Releasing Hormone Study Group. Am J Obstet Gynecol 1999;181:709-17.

7. Crowther CA, Haslam RR, Hiller JE, Doyle LW, Robinson JS; Australasian Collaborative Trial of Repeat Doses of Steroids (ACTORDS) Study Group. Neonatal respiratory distress syndrome after repeat exposure to antenatal corticosteroids: a randomised controlled trial. Lancet 2006;367:1913-9.

8. Murphy KE, Hannah ME, Willan AR, et al. Multiple courses of antenatal corticosteroids for preterm birth (MACS): a randomised controlled trial. Lancet 2008;372:2143-51.

9. Peltoniemi OM, Kari MA, Lano A, et al. Two-year follow-up of a randomised trial with repeated antenatal betamethasone. Arch Dis Child Fetal Neonatal Ed 2009;94:F402-6.

10. Asztalos EV, Murphy KE, Hannah ME, et al. Multiple courses of antenatal corticosteroids for preterm birth study: 2-year outcomes. Pediatrics 2010;126:e1045-55.

11. Crowther CA, Doyle LW, Haslam RR, Hiller JE, Harding JE, Robinson JS; ACTORDS Study Group. Outcomes at 2 years of age after repeat doses of antenatal corticosteroids. N Engl J Med 2007;357:1179-89.

12. Wapner RJ, Sorokin Y, Mele L, et al. Long-term outcomes after repeat doses of antenatal corticosteroids. N Engl J Med 2007;357:1190-8.

13. Spinillo A, Viazzo F, Colleoni R, et al. Two-year infant neurodevelopmental outcome after single or multiple antenatal courses of corticosteroids to prevent complications of prematurity. Am J Obstet Gynecol 2004;191:217-24.

14. French NP, Hagan R, Evans SF, Mullan A, Newnham JP. Repeated antenatal corticosteroids: effects on cerebral palsy and childhood behavior. Am J Obstet Gynecol 2004;190:588-95.

15. Ikegami M, Jobe AH, Newnham J, Polk DH, Willet KE, Sly P. Repetitive prenatal glucocorticoids improve lung function and decrease growth in preterm lambs. Am J Respir Crit Care Med 1997;156:178-84.

16. Moss TJ, Doherty DA, Nitsos I, Sloboda DM, Harding R, Newnham JP. Effects into adulthood of single or repeated antenatal corticosteroids in sheep. Am J Obstet Gynecol 2005;192:146-52.

17. Huang WL, Harper CG, Evans SF, Newnham JP, Dunlop SA. Repeated prenatal corticosteroid administration delays myelination of the corpus callosum in fetal sheep. Int J Dev Neurosci 2001;19:415-25.

18. Antonow-Schlorke I, Helgert A, Gey C, et al. Adverse effects of antenatal glucocorticoids on cerebral myelination in sheep. Obstet Gynecol 2009;113:142-51.

19. Dunlop SA, Archer MA, Quinlivan JA, Beazley LD, Newnham JP. Repeated prenatal corticosteroids delay myelination in the ovine central nervous system. J Matern Fetal Med 1997;6:309-13.

20. Uno H, Lohmiller L, Thieme C, et al. Brain damage induced by prenatal exposure to dexamethasone in fetal rhesus macaques. I. Hippocampus. Brain Res Dev Brain Res 1990;53:157-67.

21. Scheepens A, van de Waarenburg $M$, van den Hove D, Blanco CE. A single course of prenatal betamethasone in the rat alters postnatal brain cell proliferation but not apoptosis. J Physiol (Lond) 2003;552: 163-75.

22. Antonow-Schlorke I, Schwab M, Li C, Nathanielsz PW. Glucocorticoid exposure at the dose used clinically alters cytoskeletal proteins and presynaptic terminals in the fetal baboon brain. J Physiol (Lond) 2003;547:117-23. 
23. Whitelaw A, Thoresen M. Antenatal steroids and the developing brain. Arch Dis Child Fetal Neonatal Ed 2000;83:F154-7.

24. Newnham JP, Moss TJ, Nitsos I, Sloboda DM. Antenatal corticosteroids: the good, the bad and the unknown. Curr Opin Obstet Gynecol 2002;14:607-12.

25. Coe CL, Lubach GR. Developmental consequences of antenatal dexamethasone treatment in nonhuman primates. Neurosci Biobehav Rev 2005;29:227-35.

26. Peltoniemi OM, Kari MA, Hallman M. Repeated antenatal corticosteroid treatment: a systematic review and meta-analysis. Acta Obstet Gynecol Scand 2011;90:719-27.

27. Rees SM, Camm EJ, Loeliger M, et al. Inhaled nitric oxide: effects on cerebral growth and injury in a baboon model of premature delivery. Pediatr Res 2007;61:552-8.

28. Loeliger M, Inder TE, Dalitz PA, et al. Developmental and neuropathological consequences of ductal ligation in the preterm baboon. Pediatr Res 2009;65:209-14.

29. Dieni S, Inder T, Yoder B, et al. The pattern of cerebral injury in a primate model of preterm birth and neonatal intensive care. J Neuropathol Exp Neurol 2004;63:1297-1309.

30. Gundersen HJ, Jensen EB. The efficiency of systematic sampling in stereology and its prediction. J Microsc 1987;147:229-63.

31. Coalson JJ, Winter VT, Siler-Khodr T, Yoder BA. Neonatal chronic lung disease in extremely immature baboons. Am J Respir Crit Care Med 1999;160:1333-46.
32. Huang WL, Beazley LD, Quinlivan JA, Evans SF, Newnham JP, Dunlop SA. Effect of corticosteroids on brain growth in fetal sheep. Obstet Gynecol 1999;94:213-8.

33. Ligon KL, Alberta JA, Kho AT, et al. The oligodendroglial lineage marker OLIG2 is universally expressed in diffuse gliomas. J Neuropathol Exp Neurol 2004;63:499-509.

34. Bradl M, Lassmann H. Oligodendrocytes: biology and pathology. Acta Neuropathol 2010;119:37-53.

35. Waxman SG. Determinants of conduction velocity in myelinated nerve fibers. Muscle Nerve 1980;3:141-50.

36. Meister M, Wong RO, Baylor DA, Shatz CJ. Synchronous bursts of action potentials in ganglion cells of the developing mammalian retina. Science 1991;252:939-43.

37. Hagmann P, Sporns O, Madan N, et al. White matter maturation reshapes structural connectivity in the late developing human brain. Proc Natl Acad Sci USA 2010;107:19067-72.

38. Kumar S, Cole R, Chiappelli F, de Vellis J. Differential regulation of oligodendrocyte markers by glucocorticoids: post-transcriptional regulation of both proteolipid protein and myelin basic protein and transcriptional regulation of glycerol phosphate dehydrogenase. Proc Natl Acad Sci USA 1989;86:6807-11.

39. Tolcos M, Mallard C, McGregor H, Walker D, Rees S. Exposure to prenatal carbon monoxide and postnatal hyperthermia: short and long-term effects on neurochemicals and neuroglia in the developing brain. Exp Neurol 2000;162:235-46. 